\title{
Severe cutaneous adverse reactions: a 4-year experience in a tertiary referral hospital in Malaysia
}

\begin{abstract}
Introduction: Severe cutaneous adverse reactions (SCARs) such as Stevens-Johnson syndrome (SJS) and toxic epidermal necrolysis (TEN) are related to a variety of drugs and are associated with significant morbidity and mortality. Awareness of local clinicoepidemiology of SCARs may play a vital role in future clinical management protocols.
\end{abstract}

Methodology: A retrospective review of all patients referred to the Department of Dermatology of Hospital Tengku Ampuan Afzan, Kuantan, and Pahang, Malaysia with confirmed SCAR from 2013 to 2016 was carried out to determine the epidemiologic pattern of SCARs in the local population.

Results: A total of 25 patients with 25 reactions were seen among 7,353 new patients, yielding an incident rate of $0.34 \%$ (yearly SCAR rate range: $0.38-0.56 \%$ ), with the highest rate seen among indigenous peoples and Indians ( $0.63 \%$ and $0.62 \%$ respectively). SCARs (SJS, TEN, drug-related eosinophilia with systemic symptoms-DRESS, and acute generalized exanthematous pustulosis-AGEP) accounted for $40.3 \%$ of all cutaneous adverse drug reactions. SJS (15 cases) was the most frequent SCAR, followed by TEN (6), DRESS (2) and AGEP (2). $58.3 \%$ of patients were aged between 21 and 60 years, while the mean age was 53.7 years (range: $4-92)$. More females $(80.0 \%)$ had SJS than males $(20.0 \%)$, while TEN showed a reverse pattern $(83.3 \%$ males vs. $16.7 \%$ females). Overall, the male: female ratio was 1:1.27. Allopurinol was the commonest culprit drug causing SJS (7/15) and TEN (2/6). Antimicrobials were the predominant group which contributed to $44.0 \%$ of SCARs. One-third of our patients only took a single drug, while another third took only two drugs. Two patients died, one each from DRESS and TEN, resulting in a mortality rate of $8.0 \%{ }^{1,2}$

Conclusion: SJS was the commonest SCAR encountered in our center, while the commonest culprit drug was allopurinol. Antimicrobials as a group caused the most SCARs.

Keywords: drugs, allopurinol, symptoms, toxic epidermal, health care, patients
Volume 2 Issue I - 2018

Rajalingam Ramalingam

Department of Dermatology, Hospital Tengku Ampuan Afzan, Malaysia

Correspondence: Rajalingam Ramalingam, Department of Dermatology, Hospital Tengku Ampuan Afzan, Malaysia, Tel +60199282875 , Fax +6095 I427/2,

Email raj.blueheart@gmail.com

Received: December 22, 2017 | Published: January 18, 2018
Abbreviations: SCAR, severe cutaneous adverse reaction; SJS, stevens-johnson syndrome; TEN, toxic epidermal necrolysis; DRESS, drug-related eosinophilia with systemic symptoms; AGEP, acute generalized exanthematous pustulosis

\section{Introduction}

Severe cutaneous adverse reactions (SCARs) such as StevensJohnson syndrome (SJS), toxic epidermal necrolysis (TEN), drugrelated eosinophilia with systemic symptoms (DRESS) and acute generalized exanthematous pustulosis (AGEP) ${ }^{3}$ are associated with significant morbidity and mortality. Awareness of local epidemiology of SCARs may play a vital role in prescribing practices by health care providers. Thus, a retrospective review of all patients referred to the Department of Dermatology of Hospital Tengku Ampuan Afzan, Pahang, Malaysia with confirmed SCAR from 2013 to 2016 was carried out to determine the epidemiologic pattern of SCARs in the local population. Out of 62 cases of cutaneous adverse drug reactions referred to the Department of Dermatology of Hospital Tengku Ampuan Afzan, Pahang, Malaysia over that period of time, $25(40.3 \%)$ were SCAR, involving hospitalized patients. The high percentage is likely due to the hospital being the referral center for severe dermatology cases in the state. They were among 7,353 new patients seen during that period, yielding an incidence rate of $0.34 \%$ (yearly SCAR rate range: $0.38-0.56 \%){ }^{4}$ There were 15 cases $(60 \%)$ of SJS, six (24\%) TEN, and two (8\%) each of AGEP and DRESS
TEN was seen with equal frequency among Malays, Chinese and Indians, while the highest SCAR rate was seen among indigenous peoples $(0.63 \% ; \mathrm{p}=0.004)$ (Table 1$) .60 .0 \%$ of patients with SCAR were between 21 and 60 years old, with a mean age of 53.7 years (range: 4-92). ${ }^{5}$

Two patients died, one each from DRESS and TEN, giving a mortality rate of $8.0 \%$. More females $(80.0 \%)$ had SJS than males $(20.0 \%)$, while TEN showed a reverse pattern ( $83.3 \%$ males vs. $16.7 \%$ females); overall, the male: female ratio was 1:1.27. Allopurinol was the commonest culprit drug causing SJS (7/15) and TEN (2/6) while antimicrobials was the predominant group which contributed to $44.0 \%$ of SCARs, with Amoxycillin, Cotrimoxazole (3 cases each $)^{6}$ and Dapsone ( 2 cases) being the most frequent causative agents. One-third of our patients only took a single drug, while another third took only two drugs. Where do we stand against other regional centers? Table 2 compares clinicoepidemiological studies on SCAR in Malaysia and various Asian countries. SJS was the commonest SCAR reported in centers in South-East Asia, India and China, and accounted for two-thirds of all SCARs observed in the three Malaysian hospitals above. The mortality rate was noted to be considerably higher in the Malaysian hospitals. Antimicrobials, antiepileptics and allopurinol continue to be the major causes of SCARs in Malaysia for close to twenty years. We now know that there are specific genetic markers for carbamazepine- and phenytoin-induced SCARs, ${ }^{7,8}$ and that these alleleic markers occur with varying frequency in different ethnic 
populations. Whether this holds true for the indigenous peoples of the state of Pahang resulting in higher SCAR rates among them requires further pharmacogenomic studies. Antimicrobials being the predominant culprit group in most of the studies above not only reflects the high infectious diseases burden in tropical and subtropical Asia, but also serves to remind us of more judicious prescriptions of these agents in the future.

Table I Rates of SCAR among both Genders and Various Ethnic Groups

\begin{tabular}{llll}
\hline & No. of new patients N (\%) & No. with SCAR N (\%) & SCAR rate (\%) \\
\hline Gender & & & \\
\hline Male & $3567(48.5)$ & $1 /(44)$ & 0.31 \\
Female & $3786(51.5)$ & $14(56)$ & 0.39 \\
\hline Ethnicity & & & 0.28 \\
\hline Malay & $5697(77.5)$ & $16(64)$ & 0.51 \\
Chinese & II76(16.0) & $6(24)$ & 0.62 \\
Indian & $322(4.4)$ & $2(8)$ & 0.63 \\
Indigenous & $158(2.1)$ & $I(4)$ & 0.34 \\
Total & 7353 & 25 & \\
\hline
\end{tabular}

Table 2 Comparison of Clinicoepidemiological studies on SCAR in Malaysia and Various Asian Countries

\begin{tabular}{|c|c|c|c|c|c|c|c|}
\hline & $\begin{array}{l}\text { Beijing, } \\
\text { China } \\
\mathbf{N}=50^{\prime}\end{array}$ & $\begin{array}{l}\text { Johor bahru, } \\
\text { Malaysia } \\
\mathrm{N}=\mid 44^{2}\end{array}$ & $\begin{array}{l}\text { Singapore } \\
N=42^{3}\end{array}$ & $\begin{array}{l}\text { Klang, } \\
\text { Malaysia } \\
\mathrm{N}=33^{4}\end{array}$ & Thailand $\mathbf{N}=97^{5}$ & $\begin{array}{l}\text { Jammu, } \\
\text { India } \\
\mathbf{N}=446\end{array}$ & $\begin{array}{l}\text { Our study } \\
(20|3-20| 6) \\
N=25\end{array}$ \\
\hline Male: Female ratio & 01:00.9 & NA & I:0l & I.36:1 & 01:02.0 & I.59:1 & 01:01.3 \\
\hline Mean age (years) & $40.0 \pm 20.0$ & NA & 51.8 & $42.8(7-81)$ & 52.7 (17- 97) & $(3-65)$ & $53.7(4-92)$ \\
\hline Median latency (days) & $7.64 \pm 8.32$ & $16-28$ & $10(1-36)$ & 13.1 & NA & 3-5 weeks & 10.5 \\
\hline \multirow[t]{2}{*}{ Incidence/ Prevalence (\%) } & $\begin{array}{l}\text { Incidence: } \\
0.16\end{array}$ & Incidence: 0.34 & NA & NA & NA & NA & Incidence: 0.34 \\
\hline & $\begin{array}{l}\text { Prevalence: } \\
18.6\end{array}$ & Prevalence: 39.8 & & & & & $\begin{array}{l}\text { Prevalence: } \\
40.3\end{array}$ \\
\hline \multirow[t]{3}{*}{ Commonest SCAR (\%) } & $\begin{array}{l}\text { I. SJS } \\
(46.0)\end{array}$ & I. SJS (6I.I) & I. SJS (54.8) & I. SJS (75.8) & $\begin{array}{l}\text { I. SJS/TEN (42.3) } \\
\text { 2. DRESS }(40.2)\end{array}$ & $\begin{array}{l}\text { I. SJS } \\
(45.4)\end{array}$ & I. SJS (60.0) \\
\hline & $\begin{array}{l}\text { 2. DRESS } \\
(20.0)\end{array}$ & 2. DRESS (23.6) & $\begin{array}{l}\text { 2. AGEP } \\
(24.0)\end{array}$ & $\begin{array}{l}\text { 2. DRESS } \\
(15.1)\end{array}$ & 3.AGEP (I7.5) & $\begin{array}{l}\text { 2. DRESS } \\
(36.4)\end{array}$ & 2.TEN $(24.0)$ \\
\hline & $\begin{array}{l}\text { 3.TEN } \\
(12.0)\end{array}$ & 3. TEN (I4.6) & 3.TEN ( I I.9) & 3.TEN (9.I) & & $\begin{array}{l}\text { 3.TEN } \\
(6.8)\end{array}$ & 3. DRESS (8.0) \\
\hline \multirow[t]{3}{*}{$\begin{array}{l}\text { Commonest Groups of } \\
\text { Culprit Drugs (\%) }\end{array}$} & $\begin{array}{l}\text { I.AMs } \\
(58.0)\end{array}$ & I.AEDs (3I.9) & I.AMs (50.0) & $\begin{array}{l}\text { I.Allopurinol } \\
(33.3)\end{array}$ & I.AMs (24.7) & $\begin{array}{l}\text { I.AEDs } \\
(59.1)\end{array}$ & I.AMs (44.0) \\
\hline & $\begin{array}{l}\text { 2.AEDs } \\
(22.0)\end{array}$ & $\begin{array}{l}\text { 2.Allopurinol } \\
(26.4)\end{array}$ & $\begin{array}{l}\text { 2.Allopurinol } \\
(14.3)\end{array}$ & 2.AMs (30.3) & $\begin{array}{l}\text { 2.Allopurinol } \\
(21.6)\end{array}$ & $\begin{array}{l}\text { 2.AMs } \\
(18.2)\end{array}$ & $\begin{array}{l}\text { 2.Allopurinol } \\
(36.0)\end{array}$ \\
\hline & $\begin{array}{l}\text { 3.TCM } \\
(32.0)\end{array}$ & 3.AMs (24.3) & $\begin{array}{l}\text { 3.AEDs } \\
(11.9)\end{array}$ & $\begin{array}{l}\text { 3.AEDs } \\
(12.1)\end{array}$ & 3.AEDs (19.6) & $\begin{array}{l}\text { 3. NSAIDs } \\
(I I .4)\end{array}$ & $\begin{array}{l}\text { 3. Unknown } \\
(12.0)\end{array}$ \\
\hline Mortality rate (\%) & NA & 6.9 & 2.4 & 6.1 & 8.2 & 4.5 & 8 \\
\hline
\end{tabular}

I. SJS: Stevens-Johnson Syndrome; DRESS: Drug-Related Eosinophilia With Systemic Symptoms;TEN:Toxic Epidermal Necrolysis;AEDs:Anti-Epileptic Drugs; TCM:Traditional and Complementary Medicine; NSAIDs: Non-Steroidal Anti-Inflammatory Drugs; AMs:Antimicrobials; NA: Not Available

II. Incidence: refers to confirmed SCAR among hospitalized patients; prevalence: refers to patients with drug hypersensitivity reactions

\section{Conclusion}

SJS was the commonest SCAR encountered in our center. The commonest culprit drug was allopurinol while antimicrobials as a group caused the most SCARs. Indigenous peoples had the highest SCAR rate.

\section{Acknowledgements}

I would like to thank the staff of the department of Dermatology of Hospital Tengku Ampuan Afzan, Kuantan, Pahang, Malaysia for their hard work in compiling the relevant records. I would also like to thank the Director-General of Health, Malaysia, for his permission to publish this article. 


\section{Conflict of interest}

The author declares no conflict of interest.

\section{References}

1. Li LF, Ma C. Epidemiological study of severe cutaneous adverse drug reactions in a city district of China. Clin Exp Dermatol. 2006;31(5):642647.

2. Choon SE, Lai NM. An epidemiological and clinical analysis of cutaneous adverse drug reactions seen in a tertiary hospital in Johor, Malaysia. Indian J Dermatol Venereol Leprol. 2012;78(6):734-739.

3. Su P, Aw CWD. Severe cutaneous adverse reactions in a local hospital setting: a 5-year retrospective study. Int J Dermatol. 2014;53(11):13391345 .

4. Tee SH, Ng TG. A 5 year Retrospective Study on Clinical Patterns and Treatment Outcome of Severe Cutaneous Adverse Drug Reactions in Hospital Tengku Ampuan Rahimah, Klang, Malaysia. Malaysian $J$ Dermatol. 2014;33:9-16.
5. Klaewsongkram J, Rerknimitr P, Rerkpattanapipat T, et al. Etiologies and Clinical Characteristics of 97 Patients Diagnosed with Severe Cutaneous Adverse Reactions from Six Tertiary Medical Centers in Thailand. $J$ Allergy Clin Immunol. 2015;137(2):45.

6. Sharma R, Dogra N, Dogra D. A Clinical Study of Severe Cutaneous Adverse Drug Reactions and Role of Corticosteroids in their Management. Indian J Drugs Dermatol. 2017;3(1):20-23.

7. Lim KS, Kwan P, Tan CT. Association of HLA-B*1502 allele and carbamazepineinduced severe adverse cutaneous drug reaction among Asians, a review. Neurol Asia. 2008;13:15-21.

8. Chang CC, Ng CC, Too CL, et al. Association of HLA-B*15:13 and HLA-B*15:02 with phenytoin-induced severe cutaneous adverse reactions in a Malay population. Pharmacogenomics J. 2011;17(2):170173. 